\title{
ENTORNO HISTÓRICO Y DESTRUCCIÓN DE LA ZONA CONVENTUAL DEL MONASTERIO DE SAN MILLÁN DE LA COGOLLA, DE SUSO (LA RIOJA)
}

\author{
Begoña Arrúe Ugarte \\ Universidad de La Rioja
}

\begin{abstract}
RESUMEN: Este artículo tiene por objetivo analizar lo que fue el entorno del monasterio de San Millán de la Cogolla, de Suso, y el devenir histórico de las construcciones de la zona conventual, a partir del estudio de las fuentes documentales e historiográficas desde el siglo X, y las descripciones y reparaciones a lo largo de la edad Moderna, hasta los proyectos de restauración del siglo XX, que dieron lugar al derribo parcial de los edificios conventuales en 1967 y el definitivo de 1973. Sólo la iglesia de este monasterio se ha conservado, lo que pone de relieve la problemática de comprensión del significado y conservación de este monumento, declarado por la UNESCO en 1997 Patrimonio de la Humanidad.
\end{abstract}

Palabras clave: Patrimonio, restauración, entorno, monasterio, San Millán de la Cogolla, Patrimonio de la Humanidad.

\section{HISTORIC ENVIRONMENT AND DESTRUCTION OF THE CONVENTUAL AREA OF THE MONASTERY OF SAN MILLÁN DE LA COGOLLA, SUSO (LA RIOJA)}

\begin{abstract}
This article aims to analyze what was the environment of the monastery of Suso at San Millán de la Cogolla (La Rioja, Spain), and the historical evolution of the constructions of the convent area, from the study of documentary and historiographical sources from the 10th century, and descriptions and repairs throughout the modern age up to the 20th century restoration projects, that it gave rise to the partial demolition of the Conventual buildings in 1967 and the final of 1973. Only the Church of the monastery has been preserved, which highlights the problem of understanding the meaning and conservation of this monument, declared World Heritage Site by UNESCO in 1997.
\end{abstract}

Keywords: Heritage, restoration, environment, monastery, San Millán de la Cogolla, World Heritage Site. 
La historiografía sobre el monasterio de San Millán de la Cogolla, de Suso, desde el siglo XIX influyó notablemente en el tipo de actuaciones restauradoras que sufrió el edificio en el segundo tercio del siglo XX. Al término de este periodo el primitivo monasterio quedó despojado de la zona conventual, y su iglesia profundamente transformada, sin huella alguna de las épocas históricas de su devenir posterior al siglo XIII. Este artículo pretende recuperar la memoria de lo que fue el entorno y zona conventual del edificio de Suso, cuyos restos todavía pudimos ver en la década de los setenta del siglo XX, anotando las intervenciones más significativas y reflexionando sobre los resultados obtenidos.

La delimitación del entorno del monasterio de San Millán de la Cogolla, en sus dos edificios de Suso y Yuso, fue definida en 1999, cuando se declararon Bienes de Interés Cultural, complementándose así la declaración de monumentos histórico-artísticos recibida en 1931'. Respecto al de Suso, nada ha quedado de las diferentes construcciones de las que nos informan las fuentes medievales desde el siglo $\mathrm{X}$, y tampoco se han efectuado sondeos arqueológicos en la zona exterior del monumento que arrojen luz, a excepción de las cuatro campañas de 1970 a 1973 y su continuación en 1975², y las limitadas al estudio de la cimentación motivadas por las obras de emergencia de 1996 . Durante la de 1973 Alberto del Castillo señaló la existencia de una necrópolis al oeste de la iglesia, sin relación aparente con el monasterio mozárabe, de unos cuarenta metros de extensión, de la que se habían excavado nueve tumbas, situadas en torno a una pequeña iglesia cuyos restos habían sido descubiertos en el mes de agosto de ese año ${ }^{4}$. Los trabajos quedaron sin concluir por su fallecimiento, pero dieron como resultado final la constatación de una hipotética iglesia de construcción rectangular con muros de $105 \mathrm{~m}$ de espesor con algunos sillares, que parecía haber sido reconstruida o reaprovechada al presentar su interior relleno con dos tipos de teja, una más ancha con adornos de líneas y otra más sencilla, ligera y moderna ${ }^{5}$.

1. Decreto 12/1999, de 9 de abril, del Gobierno de La Rioja, a propuesta de la Consejería de Educación, Cultura, Juventud y Deportes (BOR, 13/04/1999, núm. 44, p. 1663). Por Resolución del 7 de agosto de 2000 de la Consejería de Obras Públicas, Transportes, Urbanismo y Vivienda se aprobó el Plan Especial de Protección de los Monasterios de Suso y Yuso, su entorno y área de influencia (BOR, 3 de octubre de 2000, núm. 123, pp. 1-39).

2. CASTILLO, A. del, "La necrópolis de covachas artificiales del monasterio de Suso, pervivencia del sistema de enterramiento eremítico". XIII Congreso Arqueológico Nacional (Huelva, 1973). Zaragoza, 1975, pp. 967-978; ANDRÍO GONZALO, J., MARTÍN RIVAS, E. y DU SOUICH, P., "La necrópolis medieval del Monasterio de San Millán de la Cogolla de Suso (La Rioja)". Berceo, 130 (1996), pp. 49-106.

3. SÁENZ PRECIADO, M. P., "Arqueología en San Millán de la Cogolla: situación actual y propuestas de intervención". Berceo, 133 (1997), pp. 141-162 y SÁENZ PRECIADO, M. P. y SÁENZ PRECIADO, J. C., "Seguimiento y sondeos arqueológicos realizados en el monasterio de Suso (San Millán de la Cogolla, La Rioja)". Estrato, Revista Riojana de Arqueología, 8 (1997), pp. 62-71.

4. CASTILLO, A. del, "La necrópolis...", p. 969.

5. ANDRÍO GONZALO, J., MARTÍN RIVAS, E. y DU SOUICH, P., "La necrópolis...", pp. 58, 81-82, y 105-106, véase también p. 103. 
A qué edificación podría corresponder y si verdaderamente era un testimonio de la continuidad de la vida eremítica entre el siglo VI y el X quedó sin respuesta al no haberse proseguido los sondeos, pese a la importancia del monumento. Lo que sí parece corroborarse por las fuentes de edad Moderna es la existencia de construcciones cuyo origen pudo remontarse, tal vez, al inicio de la documentación escrita del siglo X. Monreal Jimeno Ilamó la atención sobre un documento de la misma fecha de consagración de la "basílica", 959, para Ubieto adulterado pero de probable fondo auténtico ${ }^{6}$, en el que se mencionan cinco ermitas próximas, Ilamadas por el pueblo "cella alboheta" y citadas como monasterios, que habían sido donadas y eximidas de tributo real por García Sánchez I y su madre doña Toda, y estaban dedicadas a san Martín, Santa María, san Sebastián, san Juan, y Santa María ${ }^{7}$. Este documento podría indicar la existencia de una "laura anocorética próxima a Suso", y otro de 1071 la pervivencia más de un siglo después de dos de estas ermitas, la Santa María de Yermo, junto al río Cárdenas y la de San Sebastián, donadas por Sancho IV al presbítero Munio. La hipótesis de ubicación de estos monasterios la ofrece el padre Juan Bautista Olarte, archivero de San Millán y buen conocedor de estas fuentes, situándolos en las cercanías del término Ilamado San Martín o "corrales de San Martín", más arriba de Lugar del Río ${ }^{8}$. También Monreal alude a la opinión de fray Antonio de Yepes sobre la residencia en los riscos y cuevas de los montes Distercios de ermitaños, educados previamente en la obediencia del convento. En opinión de Yepes, antes de que se edificase en el siglo XI la casa de Yuso, "aun en aquella pequeña de arriba cabían muchos: lo uno porque ellos se contentaban con poca tierra, para gozar mucho del cielo, y lo otro, porque estaban repartidos entre aquellas cuevas y ermitas que había en la comarca, y todos hacían un gran convento tan religioso y concertado, que eran ejemplo y dechado de la perfección y observancia en aquellos siglos"

Otras referencias documentales de la década de los ochenta del siglo XIII nos indican la existencia en el coto de Suso de cementerio, enfermería con su cocina, hospital con su dormitorio, palacio, corral y palomar, y acemilería, además de una viña entre las heredades en $1221^{10}$. Apenas tenemos noticias del

6. UBIETO ARTETA, A., "Los primeros años del monasterio de San Millán", Príncipe de Viana, 132-133 (1973), p. 191, y Cartulario de San Millán de la Cogolla (759-1076). Valencia, 1976, doc. 77.

7. MONREAL JIMENO, L. A., "San Millán de Suso. Aportaciones sobre las primeras etapas del cenobio emilianense", Príncipe de Viana, 183 (1988), pp. 85-86.

8. OlARTE, J. B., Manuscritos de San Millán de la Cogolla (759-1900). Reseña y anotación, Monasterio de Yuso, 2009, formato CD, doc. 85, n. 34 y doc. 432, n. 121.

9. YEPES, F. A. de, Crónica General de la Orden de San Benito (Hyrache, 1610), Madrid, BAE, 1959, t. I, p. 82.

10. GARCÍA TURZA, C. y GARCÍA TURZA, J., Una nueva visión de la lengua de Berceo a la luz de la documentación emilianense del siglo XIII. Logroño, 1996, doc. 63 y 69, y 15 a 17. 
convento y entorno durante los siglos posteriores hasta finales del siglo XVI, aunque sirvió de santuario y lugar de retiro de los monjes benedictinos, prohibiéndose, no obstante, su uso como morada, lugar de recreo o descanso vacacional en 1564, y acogiendo a los seguidores de la Recolección de la regla en $1588^{11}$. El cercado de Suso debió terminarse en la última década del siglo, según una cédula de Felipe II otorgada a la casa en 1592 y citada en un inventario de escrituras del monasterio en el que se señala el motivo de su concesión: "para acabar de cerrar aquel sitio que está desde el monasterio de Suso hasta la hermita de San Pelayo, atento que aúa por allí muchos sepulchros de personas debotas de nuestro padre San Millán"12. En el texto de Sandoval y el similar del testimonio sobre la vida y milagros de san Millán de 1601 nada se describe de la casa de Suso, excepto que antes de llegar a ella había "vna hermita de señor sant Pelayo", que decían "se hiço para rrecordación de vna lucha quen aquel lugar hiço el buenaventurado sant Millán con el dimonio, y le vinció"13. Esta ermita es la representada en un grabado de 1608, firmado en Roma por Mattaus Greuter $^{14}$. Se dibuja al interior de la cerca que rodeaba al monasterio, próxima al acceso oriental, como una sencilla construcción rectangular cubierta a dos aguas y con cruz en el remate de la fachada occidental. El grabado muestra un camino que desde Yuso ascendía hacia esta entrada del recinto del santuario, trazado el edificio en sus perfiles fundamentales, rodeado de árboles y vegetación, y con lo que parecen otras construcciones exentas al oeste. Próxima a la cerca, asimismo al este, representa otra pequeña construcción cuadrangular con cúpula rematada en cruz. Antes de ella el camino se bifurcaba dirigiéndose hacia el oeste. Otro dibujo muy similar de $1618^{15}$, reproduce estos edificios rotulando su denominación. Así, bajo la ermita del interior se escribió "S. Pelayo" y bajo la exterior, "S. Bartolomé", pero nada en las construcciones occidentales interiores, mejor perfiladas, una a modo de crucero y otra centralizada,

11. Sobre la situación y uso del edificio durante los siglos XVI al XVIII, véase ARRÚE UGARTE, B., "Conservación del monasterio de San Millán de la Cogolla, de Suso (La Rioja), durante la Edad Moderna" en VÉLEZ CHAURRI, J. J., ECHEVERRÍA GOÑI, P. y MARTíNEZ DE SALINAS OCIO, F. (ed.), Estudios de Historia del Arte en memoria de la profesora Micaela Portilla, Vitoria-Gasteiz, 2008, pp. 521-531.

12. Archivo Histórico Nacional (en adelante AHN), Códices, L. 1034, fol. 260 v. (en Nájera, 1592, refrendada por Gerónimo Gassol).

13. SANDOVAL, P. de, Primera parte de las fundaciones de los monasterios del glorioso padre San Benito..., Madrid, 1601, fol. 23 r., y AHN, Clero, leg. 3102 ("Milagros, 0.2.1.4.").

14. Conservada la plancha en el monasterio de Yuso; reproducida en SÁENZ PRECIADO, M. P., "Arqueología...", p.148, foto 3 y BENITO MARTíN, F. y SANCHO RODA, J., "El monasterio de Suso. San Millán de la Cogolla. Estudios de investigación para una futura intervención integral". Berceo, 133 (1997), p. 167, foto. 2.

15. Dado a conocer por CADIÑANOS BARDECí, I., "El monasterio de San Millán según un dibujo de comienzos del siglo XVII" en Actas VI Jornadas de Arte y Patrimonio Regional. Los monasterios de San Millán de la Cogolla. Logroño, 2000, pp. 275-282. 
también con cruz de remate en su cubierta. En la ladera, rellena de árboles diseminados y entre ellos la figura de un cérvido, se representó al oeste, próxima al río Pazuengos, "La Casa de la Muñeca"; algo más al sur, un "Corral del Ganado"; al sur de él, la ermita de "S. Andrés", y al este, el "Hospital del Monasterio", completándose el dibujo con otras ermitas hacia el barrio del Río, Barrionuevo (villa de San Millán) y Berceo, dominando el conjunto la vasta edificación del monasterio de Yuso ${ }^{16}$. Por el estudio del padre Olarte sabemos que el grabado y dibujo reproducen los límites de la abadía, una vez que se dictó sentencia a su favor en el pleito iniciado el 29 de agosto de 1604 y mantenido con las parroquias unidas del valle (Berceo, Estollo y San Andrés), en relación con los límites de la jurisdicción civil y los derechos de pastos ${ }^{17}$. En Roma, hasta donde se había extendido el litigio, se encontraba fray Andrés de Salazar, monje emilianense, quien encargó el grabado, y allí se elaborarían hacia 1604 tres mapas que servirían a la defensa del monasterio, las parroquias y el perito neutral $^{18}$. En el presentado por el monasterio se representa de forma esquemática el edificio de Suso, con dos caminos de acceso, uno desde Yuso y otro desde la villa; hacia el suroeste la casa o granja de la Muñeca; al este de ella, el hospital y al sur de éste, la ermita de San Andrés (Lám. 1).

Respecto a la ermita de San Pelayo, se conserva en el archivo de San Millán un cuadernillo de cuatro hojas relativo a la "Regla de la Cofradía de Santa Lucía y Señor Santo Pelayo, de la Villa de San Millán. Año 1505", trascrito el 11 de enero de 1705, con aprobación del abad Plácido Vea. Los priores de esta cofradía -Pedro de Villaverde y Andrés de Monasterio- y las fincas que gestionaban se documentan en 1628, 1631 y $1668^{19}$. Parece evidente que la advocación a santa Lucía sobresalió, frente a la de san Pelayo. Así, fray Mateo de Anguiano en su compendio de santuarios de la provincia destacará sus ruinas en la descripción del entorno a comienzos del siglo XVIII: "El Monasterio grande, y que lo es por todas sus circunstancias, está en llano, y a pocos passos del está la casa que llamaron, antes de fundarse, Hospedería, o enfermería, la qual es muy pequeña. Subiendo a lo alto, a cosa de vn tiro de piedra del Oratorio ["que hoy Ilaman el Monasterio de Susso"] huvo vna pequeña hermita de S. Lucía, cuyas ruynas se ven, y allí vna piedra, que da razón como en esse sitio luchó el Demo-

16. Algo apunté en "Entorno y dependencias conventuales del monasterio benedictino de San Millán de la Cogolla de Yuso a mediados del siglo XVII" en Actas de las VII Jornadas de Arte y Patrimonio Regional. El pintor Fray Juan Rizi (1600-1681). Las órdenes religiosas y el arte en La Rioja. Logroño, 2002, pp. 204-206.

17. OLARTE, J. B., Manuscritos..., doc. 4719 (el pleito fue promovido por el obispo de Calahorra Pedro Manso a través de los clérigos de las parroquias, con el apoyo del cabildo calceatense).

18. Conservados en el archivo de San Millán, de 76 × 53,5 cm y anotados en italiano (OLARTE, J. B., Manuscritos..., doc. 4719).

19. OLARTE, J. B., Manuscritos..., doc. 8347, 8698, 9675 y 11031. 


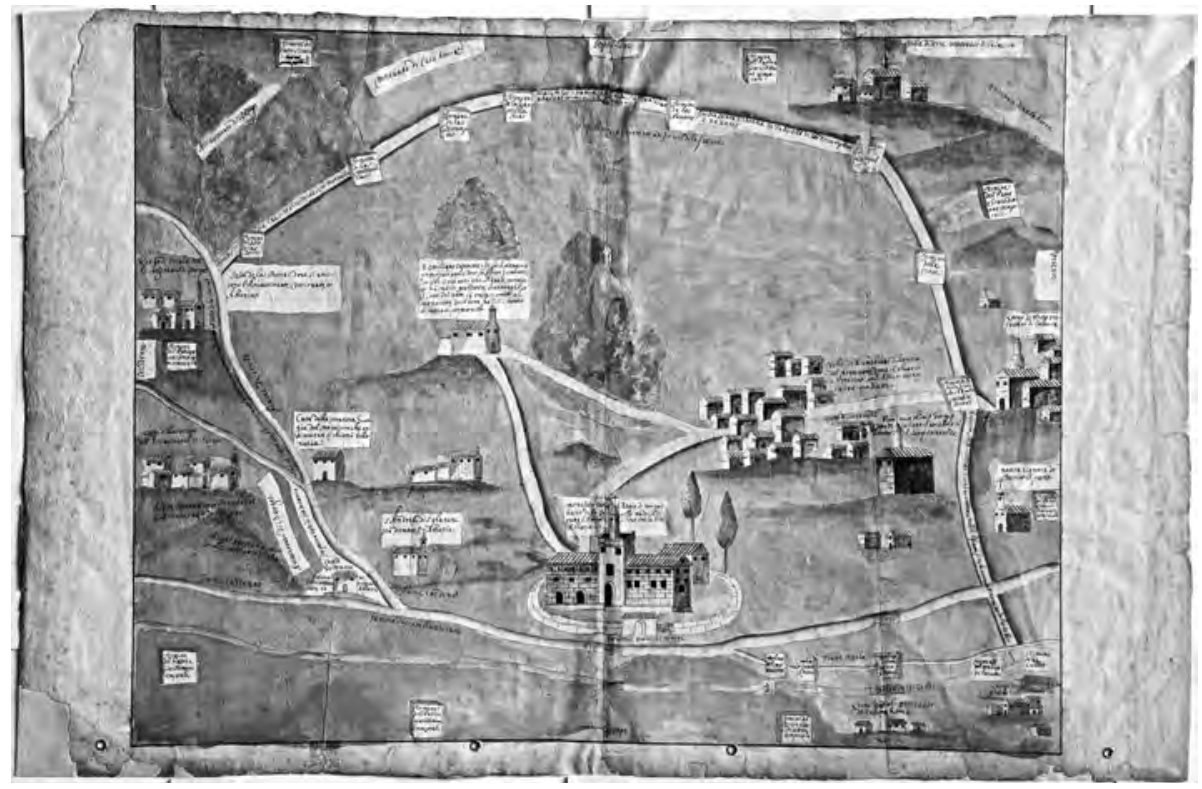

Lámina 1. Mapa de la jurisdicción de la abadía de San Millán de la Cogolla, Roma, h. 1604 (ASM; foto Artempus).

nio con el Santo, y le venció este, según se lee en su Vida"20. Este lugar es citado por fray Diego Mecolaeta, transcribiendo la inscripción de la lápida, situada a unos treinta pasos antes de llegar al monasterio ${ }^{21}$. La inscripción aún puede verse en un sillar, que parece reutilizado y forma parte del pedestal de una cruz de hierro, situada al sur del camino de acceso actual al monasterio: "AQUÍ VENCIO/ SAN MILLAN/ VISIBLEMENTE/ A SATAN"22 (Lám. 2). Fue, asimismo, trascrita por Jovellanos cuando visitó el monasterio en la primavera de 1795, situándola en el frente de "una columna o pilastra cuadrada y alta", que vio "antes de llegar al convento, junto y a la derecha del camino" ${ }^{23}$. Ninguna otra

20. ANGUIANO, Fr. M. de, Compendio historial de la provincia de la Rioja, de svs santos y milagrosos santvarios, Madrid, 1701 y reimp., Antonio González de Reyes, 1704 (edición facsímil, Logroño, 1985, lib. Il., cap. 6, p. 473).

21. MECOLAETA, Fray Diego, Desagravio de la verdad en la Historia de San Millán. Madrid, 1724, p. 77.

22. Debe tratarse del monolito "hasta hace poco sumergido en el asfalto" recuperado en la intervención de 2002 (DURALDE RODRÍGUEZ, J. R., "Restauración del Monasterio de Suso", Proyectar La Rioja, 22 (Logroño, COAR, 2002), p. 67 y 33 (2006), p. 215.

23. JOVELLANOS, G. M. de, Obras III. Diario Sexto (1795-1796). Itinerarios X al XII. BAE, Madrid, 1956, t. LXXXV, p. 278. 
memoria queda de la ermita, celebrándose en Suso romerías a santa Lucía al menos hasta las primeras décadas del siglo XX, descendiendo progresivamente este culto a lo largo del mismo. Una imagen de esta santa se inventarió entre los objetos de culto del monasterio de Suso en 1822, que se trasladarían a las iglesias del valle, quedándose ésta en San Millán, y no apareciendo ya en el inventario de $1835^{24}$. En cuanto a la ermita de la Muñeca sabemos que en ella se celebraron las sesiones previas del acuerdo de usos y derechos entre los concejos de San Millán y Pazuengos de 1596, pudiendo tratarse para el padre Olarte de alguna de las edificaciones mencionadas en los documentos del siglo $X^{25}$. La ermita de San Andrés tal vez sea la que formada parte de una heredad arrendada por el monasterio de San Millán en 1618 a unos vecinos de Lugar del RíO ${ }^{26}$.

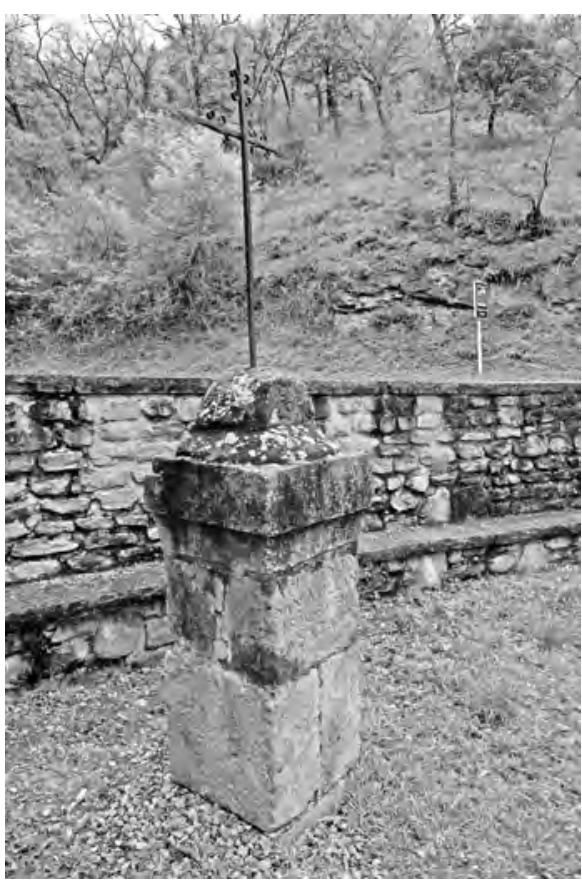

Lámina 2. Cruz con inscripción en el camino de acceso a la iglesia de San Millán de Suso, en 2013.

En el apeo de heredades del monasterio de San Millán, Ilevado a cabo en los meses de mayo, septiembre y octubre de 1671 por provisión de Carlos II, a petición del abad y convento, se registran buena parte de las ermitas y construcciones antes mencionadas ${ }^{27}$. En septiembre se apeó Lugar del Río y alrededores, anotándose los solares antiguos de las ermitas de San Sebastián y Santibáñez, y una heredad frente al río de la Muñeca, donde se junta con el de Pazuengos. En los pagos de Cabañares, a la margen derecha del río Cárdenas hacia el este, se acabada de reedificar la ermita de San Martín del Castillo, por haberse arruinado la anterior; en torno a ella estaban las ruinas de la ermita de Santa María y hacia arriba del monte, la de Santa Coloma. En la villa de San Millán, en el Ilamado "parral de Suso", se seña-

24. ASM, Libro de asuntos varios, descosido.

25. OLARTE, J. B., Manuscritos..., doc. 3815; véase doc. 86, nota 35, sobre la delimitación del coto exento del monasterio por García Sánchez I (14 de mayo de 959).

26. OLARTE, J. B., Manuscritos..., doc. 6544 (renta de San Andrés de Villanueva).

27. Archivo de San Millán de la Cogolla (en adelante ASM), Simón Barrueta, 1670-1673, leg. G 17, fols. 31 r.-77 v.; dehesa de Suso en fol. 75 r.-77 r. (cuadernillo foliado a parte, provisión real en fol. 1 r.-2 v. y notificaciones a las distintas localidades en fol. 3 r.-31 v.). 
ló una nevera y una era cercada de calicanto, y dentro de la "dehesa San Millán de Suso", que se extendía desde la Puente del Torco, situado sobre las casas de la lavandería ("que es arriba del monasterio en fin de los paredones que suben de él hacia Suso"), se apeó el monasterio de San Millán de Suso con las ermitas de San Andrés y Santa Lucía, unos corrales para el ganado y los solares de la casa de la Muñeca con tierras de labranza.

La mayor parte de las ermitas se encontraban arruinadas a finales del siglo XVII. Incluso antes, un acuerdo del Consejo del monasterio de 1627 indica que algunas que tenía la casa estaban "casi perdidas", decidiendo su reparación ${ }^{28}$. En 1683 se reedificaron las ermitas de San Martín del Monte y de San Sebastián de Lugar del Río. En la primera se hizo nuevo el tejado en 1703, junto con el del corral de San Martín; y en 1718 se llevaron "los despojos de la hermita de San Martín" a la casa de recreación de San Martín de Soto. Los tejados de la segunda se repararon en 1699, 1704 y 1764, efectuándose arreglos menores en $1722^{29}$. Ninguna otra noticia se ha documentado de las anteriormente citadas. No hemos encontrado alusión a ellas en la obra de Mecolaeta de 1724 cuando escribe sobre el entorno de Suso: "Está fundado el Convento en una angosta garganta, que forma una loma del Distercio, que mira a la parte Septentrional, en un terreno escabroso, que tiene de latitud como un tiro de piedra. Subese a el por la parte de medio día con penalidad, por ser el camino muy costanero. Está sitiado el Monasterio de varias lomas, que forma el monte, $y$ tiene a un costado una pequeña fuente. La fábrica de el está arrimada a la frente de un gran peñasco, en que hay diferentes cuebas ${ }^{\prime \prime 30}$. Tampoco Jovellanos menciona nada en torno a Suso a finales del XVIII. No obstante, merece la pena destacar sus observaciones durante el camino de subida al santuario, con "notables tongadas de peña en la altura; su composición, pedazos de varios tamaños angulosos, de piedra graño, pizarra, piedra caliar y cuarzo, todo aglomerado en un lecho de tierra roja, y aun lo es la arena". En la bajada por otro camino escribirá: "iqué abundancia de tomillo, espliego, orégano y otras plantas olorosas! ¡Qué vista tan risueña la del

28. AHN, Clero, Lib. 6086 (Libro de actas del Consejo, 1626-1640), fol. 9 v.

29. AHN, Clero, Lib. 6035 ("Libro del gasto que se hace en las obras de este Real Monasterio de San Millán de la Cogolla", 1675-1769), s.f. No aludo a otras ermitas de la villa, como la de Santa Potamia y San Jorge, con variadas intervenciones, o la de Nuestra Señora del Espino, esta última derribada en 1752.

30. MECOLAETA, Fray Diego, Desagravio..., p. 97. Recientemente Fernando Gutiérrez, a quien agradezco la información e intercambio de noticias, ha publicado una parte de su manuscrito sobre la historia de algunos santos emilianenses, a partir de la copia que hizo el padre Enrique Pérez (probablemente entre 1908 y 1920), pero no la descripción del camino de Yuso a Suso que, tal vez, podría interesar al conocimiento del entorno, citando, eso sí, la penosa cuesta de subida, la fuente y el jardín (GUTIÉRREZ BAÑOS, F., "San Millán de la Cogolla: el monasterio de Suso a principios del siglo XVIII" en Alma Ars. Estudios de arte e historia en homenaje al Dr. Salvador Andrés Ordax. Valladolid, 2013, pp. 151-156). 
río Cárdenas, que allá en el fondo corre por una estrecha pero frondosa vega llena de árboles y verdura! El monasterio, también abajo, a la izquierda; a la derecha la montaña de San Lorenzo, cubierta aún de nieve, y por todo el camino muchos y grandes robles con su agradable sombra" ${ }^{\prime \prime 2}$.

En cuanto a la casa conventual, las noticias de la edad Moderna sobre obras o reformas son muy precarias. Algunas señalé en relación con las efectuadas en la iglesia, espacio en el que se ha centrado fundamentalmente la historiografía del monasterio. Así, en 1682 la realización de un tabique en el salón del convento y una chimenea, junto con las reformas de las cubiertas; retejado y arreglos de tejados en 1689, 1690 y 1693 ; ejecución de una pared de calicanto y un nuevo cuarto en 1695; construcción de un paredón en el camino para control de las aguas y una cava para conducirlas, porque dañaban la nueva pared, en 1701, año en el que se abordaron nuevos arreglos de envergadura en los tejados; realización de un nuevo cenador de madera y albañilería enlucida, una nueva celda adentro de la cocina, con un gran pedazo de pared que miraba al monasterio de abajo, enlucido y enladrillado de celdas, renovación de ocho puertas y dos ventanas con su herraje y, además, el largo paredón en que estribaba la casa en 1708, obras correspondientes al abadiado de fray Plácido Vea en atención a las mandas y herencia del Cardenal Aguirre; nuevos celda y cuarto se ejecutaron en 1718 y 1729 , y un paredón sobre la iglesia en 1728; un óculo con reja sobre la puerta de salida a la fuente se hizo en 1765 y una lucerna, de ubicación desconocida, al año siguiente; al margen de arreglos continuados de los tejados, otras obras de reparación, estimadas en unos cincuenta ducados, acordó el Consejo del monasterio en $1781^{32}$.

La situación del monasterio de Suso en el siglo XIX ha sido en más de una ocasión valorada ${ }^{33}$. Ciñéndonos al objetivo de este artículo, las fuentes nos hablan de distintas reformas y reparaciones en la casa conventual, y otros inmuebles del entorno. En tiempos del abad Íñigo Villanueva (1814-1818), después del cuatrienio de 1809-1813 de obligada ausencia de los benedictinos, se procedió a rehabilitar la casa, limitándose en Suso a la reparación del corral de subida al convento, retejándolo y poniéndole nuevas puertas ${ }^{34}$. De nuevo deshabitados los edificios entre diciembre de 1820 y julio de 1823, en el expediente de enajenación de predios del suprimido monasterio, realizado en agosto de 1821 por el

31. JOVELLANOS, G. M. de, Obras III..., pp. 278-279.

32. ARRÚE UGARTE, B., "Conservación del monasterio...", pp. 526-529.

33. Véase MOYA VALGAÑÓN, J. G., "La protección del patrimonio cultural en La Rioja en el siglo XIX y comienzos del XX" en VÉLEZ CHAURRI, J.J., Echeverría Goñi, P. y MARTíNEZ DE SALINAS OCIO, F. (ed.), Estudios de Historia del Arte en memoria de la profesora Micaela Portilla, Vitoria-Gasteiz, 2008, pp. 511-519.

34. AHN, Clero, Lib. 6074 (Libro de depósito del monasterio de San Millán de la Cogolla, 1814-1835), s.f. 
juzgado de Primera instancia de Santo Domingo de la Calzada, ante el escribano Manuel Baltasar del Valle, se registra el antiguo monasterio de Suso "con su yglesia y demás oficinas a él correspondientes, sito todo en la dehesa llamada del Abad". Los tasadores Faustino Velasco y Francisco Angulo, maestros de obras, lo valoraron en 62.584 reales. Asimismo se tasó una era con su cerca de pared para trilla en el Ilamado Parral de Suso, y un pequeño edificio que fue nevera, contiguo a ella ${ }^{35}$. También se realizó en 1822 un inventario de los bienes muebles existentes en Suso, algunos de los cuales se trasladaron al monasterio de Yuso, donde se mantuvo la parroquia de la villa, y a las iglesias de Estollo y Lugar del Río ${ }^{36}$. Tras el regreso de los monjes en 1824, una atención especial recibió el santuario en 1828, siendo abad Albito Petite, intervención tal vez salvadora de la ruina en que se encontraba después de la última exclaustración ${ }^{37}$. El documento lo di a conocer en $2000^{38}$, y por la memoria de las obras se pueden deducir las perentorias necesidades que mostraba el conjunto del edificio. Fue preciso recalzar gran parte de los muros, revocándolos por fuera y enluciéndolos al interior; retejarlo en su totalidad y renovar puertas y ventanas con sus correspondientes herrajes y cristales. La casa conventual debió recibir una rehabilitación cuyo alcance desconocemos, pues se indica la construcción de muchos tabiques para la nueva y mejor distribución de las habitaciones del piso alto, además de la reforma de la cocina (nuevo hogar, fregadero y cañón) y la secreta (incorporándola al resto del edificio y dándole acceso por el interior de éste), y la colocación de nuevos herrajes en diferentes ventanas. En la entrada occidental se dispuso una puerta con cerraja y en el recibidor que había, asientos y una mesa de piedra. Al exterior, se menciona una plazuela, en la que se formaron dos poyos, y la puerta que se hizo en el pasadizo de la huerta, donde se plantaron varios árboles, al igual que en los alrededores; un nuevo encañado condujo la fuente a un punto diferente del anterior, limpiándose los caminos de acceso al monasterio. No se detallan otros reparos, al margen de los obrados al interior de la iglesia, conducentes a su mejora y conservación.

Entre 1835 y 1878 la historia nos relata un cúmulo de despropósitos, fruto en buena parte de la descoordinación entre la administración central y provincial, la falta de medios económicos y humanos e, incluso, el desconocimiento

35. AHN, Clero, Leg. 3097.

36. ASM, Libro de asuntos varios, descosido (2 fol.).

37. Fue posible gracias al apoyo económico de fray Citonato Álvarez, quien por carta del 20 de octubre de 1835, cuando tenía 74 años, solicitó la devolución del préstamo de 6.121 reales que le había solicitado el abad para la restauración "del santo oratorio de Suso tan destruido y despojado de todo", al regreso de los monjes (ASM, Legajo de correspondencia de temas diversos, s.d. / 1826-1842).

38. ARRÚE UGARTE, B., "Apuntes sobre patronazgo y conservación del patrimonio artístico del monasterio benedictino de San Millán de la Cogolla". Actas de las VI Jornadas de Arte y Patrimonio Regional. Los monasterios de San Millán de la Cogolla. Logroño, 2000, pp. 162-163. 
de la existencia de dos conjuntos arquitectónicos, Suso y Yuso, que siempre habían formado parte de una misma entidad pero que, como sucede en la actualidad, dejaron de depender de un mismo titular en el siglo XIX, lo que no ha dejado de tener consecuencias significativas en la conservación de este patrimonio. Sobre el entorno y las construcciones anejas a la iglesia apenas hay noticias de relieve. El abandono dio lugar a la tala indiscriminada de árboles de la dehesa. Una causa mantuvo el ayuntamiento de San Millán contra diferentes vecinos por este motivo entre 1838 y $1841^{39}$. En 1842 se arrendaron los pastos de la dehesa. Finalmente salió a subasta pública el conjunto en $1845^{40}$. La dehesa tenía una extensión de 1.728 fanegas y 6 celemines de tierra de pasto, y comprendía 3.160 pies de roble, 120 hayas y dos viveros de 105 fanegas, donde podían mantenerse 600 cabezas de ganado lanar, 160 de vacuno y 50 de mular. En ella se incluía un edificio ruinoso, "titulado Convento de Suso" y un corral muy deteriorado "cubierto de teja vana". El comprador de 1846 invirtió cerca de veinte mil reales en su reparación, retejándolo en su totalidad, levantando los pisos y rehabilitando los vanos y rejas, así como la fuente ${ }^{41}$. Aunque esta venta quedó sin efecto por Real Orden de 1851, el entorno natural sufrió una importante pérdida con la cesión de la dehesa para cortar y carbonear 600 robles y 100 hayas con su ramaje para uso de la ferrería de Lugar del Río en 1854. Pese al nombramiento de un guarda o conserje para la conservación de los edificios emilianenses ${ }^{42}$, y las reclamaciones de la Comisión Provincial de Monumentos al Gobernador Civil y la Academia de Bellas Artes de San Fernando, volvieron a salir a remate los pastos de la dehesa, la casa contigua al monasterio y el corral en 1857, 1860, 1863 (cesión mancomunada) y 1867. La Academia consideraba necesaria su conservación pero la idea que parece traslucirse de los informes y escritos era que el convento e iglesia de Suso se soportaban recíprocamente, que estaban bien atendidos por los conserjes y la Diputación Provincial, que no podía servir ni para museo, ni biblioteca, a diferencia del de Yuso, y que no se encontraba con el deterioro denunciado, según

39. Las referencias a las fuentes documentales de las noticias proporcionadas a continuación se encuentran en el corpus documental encargado por la Consejería de Educación, Cultura, Juventud y Deportes a las investigadoras del Instituto de Estudios Riojanos M. ${ }^{a}$ Jesús Martínez Ocio y M. a Cruz Navarro Bretón: Estudio de fondos documentales relativos al monasterio de Suso en San Millán de la Cogolla, Logroño, 2001 (inédito), doc. 42 a 46, 50, 54 a 85 y 86 a 94.

40. Boletín Oficial de la Provincia de Logroño, del 18 de mayo de 1845 (véase MALDONADO Y COCAT, R. M., "En 40.000 reales fue tasado el monasterio de San Millán de Suso". Berceo, 12 (1949), pp. 453-455).

41. Véase NAVARRO BRETÓN, M. C., "El patrimonio artístico riojano en el siglo XIX, a través de la Comisión Provincial de Monumentos" en ARRÚE UGARTE, B. (coord.), Aspectos menos conocidos del arte riojano. Logroño, Ateneo Riojano, 2000, pp. 210-213.

42. El padre Joaquín Peña destacará la labor de los benedictinos que se encargaron del cuidado de Suso después de la desamortización, en San Millán de la Cogolla. Páginas de su historia, Logroño, 1980; reed. 1994, pp. 254-255. 
opinión de Pedro de Madrazo tras su visita de 1865, para quien era suficiente con no renovar el arrendamiento. No obstante, las obras provinciales de mantenimiento constatadas fueron escasas y no de gran alcance, como la de 1863 (834 reales y 20 céntimos) y la de 1866 (1.768 reales), limitada la primera a los tejados, los cuales sufrieron un incendio, al parecer intencionado, en 1860. Los peligros venían de todos los lados, pues por una carta del conserje fray Faustino Matute de abril de 1862, parece ser que había intención de aprovechar los pequeños huertos inmediatos al edificio y beneficiarse de la olmeda de uno de ellos, lo que, según él, ponía en riesgo de hundimiento la construcción si se talaban los olmos que le servían de fundamento, por lo que rogaba al Gobernador Civil que no se cediesen los terrenos, cuya medición ya se había efectuado. Cuando Francisco Navarro Villoslada denuncie en 1863 en El Pensamiento Español las vicisitudes de este patrimonio, comentará que la ladera de la Cogolla era un cementerio: "No hay manera de cruzarla, sin hollar huesos humanos, que asoman entre las piedras descarnadas por los torrentes; y al visitar días pasados el venerado santuario, yo mismo recojí alguno de esos restos humanos, que contaba a no dudarlo siglos y siglos de antigüedad"43.

Los dos años de estancia del Colegio de Misioneros Franciscanos de Bermeo, a los que el Ministerio de Ultramar había dado el monasterio (Real Orden de 14 de mayo de 1866) e incautó el de Hacienda (Decreto del 16 de noviembre de 1868), tampoco debieron suponer ningún beneficio, aunque la Diputación Provincial les instó a que se encargasen de la conservación de Suso. Una noticia de El Avisador Logroñés de 1867 informaba de que "una de las fachadas del antiguo monasterio de Suso" amenazaba ruina, hecho por el que la Comisión Provincial había dispuesto que su arquitecto reconociese el edificio y propusiese lo conveniente para salvar el histórico monumento ${ }^{44}$. Diez años después, en 1877, el conserje Agustín Quintana recibió, con carácter de préstamo, 350 tejas del cura ecónomo de la parroquia de Yuso para reparar los tejados ${ }^{45}$. Al año siguiente se instaló en Yuso el Colegio de Agustinos Recoletos, pero había mucho que hacer y rehabilitar en el monasterio de abajo. Hasta 1904 no se elaborará el primer proyecto de restauración del de arriba, encargado por la Sección de Construcciones Civiles del Ministerio de Fomento, al arquitecto Joaquín Roncal, limitado, por otro lado, a la iglesia. Pese a que se ha pensado que no se llevó a cabo, Garrán mencionará la ejecución de obras en 1906, lamentando la actua-

43. NAVARro VILlOSLADA, F., "El Escorial de La Rioja", El Pensamiento Español (1863), reproducido en el Boletín Eclesiático del Obispado de Calahorra y la Calzada, núm. 30 (12 de septiembre de 1863), p. 266, y en CAPELLÁN DE MIGUEL, G., "El monasterio de San Millán y la desamortización", Berceo, 140 (2001), pp. 339-348.

44. El Avisador Logroñés, Año I, núm. 2, 10 de diciembre de 1876, sección Noticias, p. 2.

45. ASM, Leg. $6^{\circ}$, Libro de cuentas de fábrica de la iglesia parroquial de San Millán de la CogoIla, 1852-1886, y otros documentos variados, fol. $1^{\circ}$ de los documentos cosidos al final del libro. 
ción del sobrestante, sin duda Manuel Jiménez Escudero, quien le había informado en 1904 del presupuesto y pedido que instase a Roncal para que lo presentase y consiguiese que se efectuase por administración, evitando así la larga tramitación del expediente y pudiéndose iniciar los trabajos sin esperar la formación integra del proyecto. Al referirse a las tres cuevas existentes en el nivel superior a las que se subía por el coro, escribirá: "Cada una tenía su lápida especial en su respectivo sitio. Pero el sobrestante del Ministerio de Bellas Artes, al hacer las reparaciones de 1906, las fue arrancando de sus propios lugares, y las puso a la entrada, todas juntas, para que se leyeran a la luz natural, y sin necesidad de bujías ni fósforos (sic); ¡Y el Arquitecto se lo consintió!./ Más para que no se pierda la memoria de cada lugar, hay que volver a colocar aquellas lápidas en los puntos de que las quitó el indicado Sobrestante" ${ }^{\prime 46}$. Así mismo, Manuel Gómez Moreno se referirá a obras recientes, criticando la decisión de mantener los enlucidos en la fábrica de mampostería de la iglesia ${ }^{47}$.

La imagen que ofrece Vicente Lampérez en 1907 del exterior del monasterio es muy elocuente, pues de sus escritos se derivaron en gran parte las actuaciones del siglo XX, tanto de la zona conventual, como de la iglesia. Así, dirá: "Visto por el exterior y en conjunto, el santuario de San Millán de Suso, más parece una gran casa de labor, que un edificio eclesiástico. Pegados a la roca del monte que les da fondo, destácanse varios cuerpos pobres y sin carácter, con huecos inexpresivos, blanqueos igualitarios y vulgares tejados... al oeste de ella [la iglesia] un conjunto de dependencias sin importancia, que no pudieron ser nunca el monasterio viejo, como alguien ha supuesto, porque son modernísimas con relación al tiempo en que dejó de haberlo en Suso". Continúa con la fachada oriental, describiendo el cuerpo bajo de la sacristía con la cueva de Santa Áurea como cabecera, y el vestíbulo con las dependencias altas al sur, "sin valor alguno"48. Realizará una reconstrucción de la fachada sur de la iglesia (que llevará a la práctica Francisco Î́niguez) y dibujará una planta de la misma (rectificando la de Roncal), pero a partir de él, ninguna planta se levantará de la zona conventual. Por su parte, Gómez Moreno coincidirá en la carencia de interés de las construcciones adosadas a la iglesia: "Forma un conjunto de construcciones vulgares, del que sobresalen escasamente las cumbres de su iglesia, con una ridícula

46. GARRÁN, C., San Millán de la Cogolla y sus dos insignes monasterios. Logroño, 1929, pp. 23-24.

47. "En recientes obras de reparación ha podido omitirse cal en la iglesia, deshacerse algunas partes desfavorables y sin arte, como sus bóvedas tabicadas del siglo XVIII, que encubren los altos del edificio, y explorar algo de lo encubierto y maltrecho; pero se malogró la ocasión, reduciéndose lo bueno a descubrir dos capiteles interesantísimos" en GÓMEZ-MORENO, M., Iglesias mozárabes. Arte español de los siglos IX a XI. (Madrid, 1919), Granada, Patronato de la Alhambra, 1975, p. 296.

48. LAMPÉREZ Y ROMEA, V., "La iglesia de San Millán de la Cogolla de Suso (Logroño)", Boletín de la Sociedad Castellana de Excursiones, V, 59 (1907), pp. 246- 247. 
torrecilla, y cuyo revoco reciente le ha robado el escaso matiz de vejez y monumentalidad que antes acusara. Por dentro la impresión sigue siendo desfavorable en términos de que sólo a fuerza de abstracciones lógrase reconocer allí algo de valor, algo emocionante, fuera del paisaje, que éste sí vale y mantiene la prez de las tradiciones emilianenses" ${ }^{\prime 49}$. En este apreciado paisaje comentará Garrán la existencia de "catorce Capillitas en el camino de Yuso a Suso", para poder rezar frente a ellas el Vía Crucis ${ }^{50}$. El agustino fray Miguel Avellaneda mencionará en su guía-homenaje escrita en el centenario de la exclaustración (1935), cómo aún podían verse "pequeños claustros, habitaciones y dependencias", recuerdo de la morada de los monjes benedictinos ${ }^{51}$.

Las fotografías del primer tercio del siglo XX son testimonio del conjunto monástico de San Millán de Suso. La publicada en el libro de Garrán muestra la casa conventual desde el sudoeste ${ }^{52}$, un volumen rectangular de altura inferior al de la iglesia, adosado al oeste de ella, y al de dos plantas meridional, que cobijaba el vestíbulo al sur. La toma de Pelai Mas, de 1932-1933, permite completar esta visión ${ }^{53}$. La casa de dos plantas presentaba en la superior cuatro vanos adintelados de mayor tamaño (uno cegado) en alternancia con otros menores, a la manera de las celdas benedictinas del edificio de Yuso; en la inferior, una puerta flanqueada de otros dos vanos, todos adintelados y remarcados, daba salida directa al camino occidental, mientras que otro parece correr paralelo y dirigirse a la entrada oriental de la iglesia. Estaba cubierta a tres aguas, con una chimenea cuadrangular en la vertiente meridional y una buhardilla próxima al ángulo sureste. Los muros parecen mostrar la mampostería con pérdida del enfoscado, al igual que los de otra construcción más al oeste y de menor volumen, con tejado independiente, en la que se abría un acceso en el muro occidental en arco rebajado y dos ventanas adinteladas en el meridional. La vegetación no permite mayor descripción, pero podría tratarse de alguna de las construcciones dibujadas a comienzos del siglo XVII. Las tarjetas postales de la época y las fotografías anteriores a 1967 muestran esta configuración de la fachada suroeste (Lám. 3).

Tras la declaración de 1931, el edificio de Suso comenzará a sufrir las obras de intervención de mayor envergadura y, con ellas, la drástica y progresiva transformación de su identidad monástica. Ni las dependencias occidentales, ni la planta superior del vestíbulo, que debió servir a la casa, han Ilegado hasta nosotros. Esta última fue eliminada durante la restauración de 1934-1935 dirigida por Francisco

49. GÓMEZ-MORENO, M., Iglesias mozárabes..., p. 296.

50. GARRÁN, C., San Millán de la Cogolla..., p. 21.

51. AVELLANEDA, M., Guía del turista del libro El Escorial de la Rioja. Morachil (Granada), 1935, p. 10.

52. GARRÁN, C., San Millán de la Cogolla..., p. 2.

53. Fondo Fotográfico, Instituto de Estudios Riojanos, núm. inv. 1.0948. 
Lámina 3. Vista del Monasterio de San Millán de la Cogolla, de Suso, desde el suroeste. Arriba, antes de 1934 (detalle de tarjeta postal de Unión Postal Universal, no 3553, colección particular) y abajo, entre 1935 y 1967 (detalle de foto de Gonzalo de Miguel Ojeda (Photo Club); Fondo fotográfico IER, 01/215).
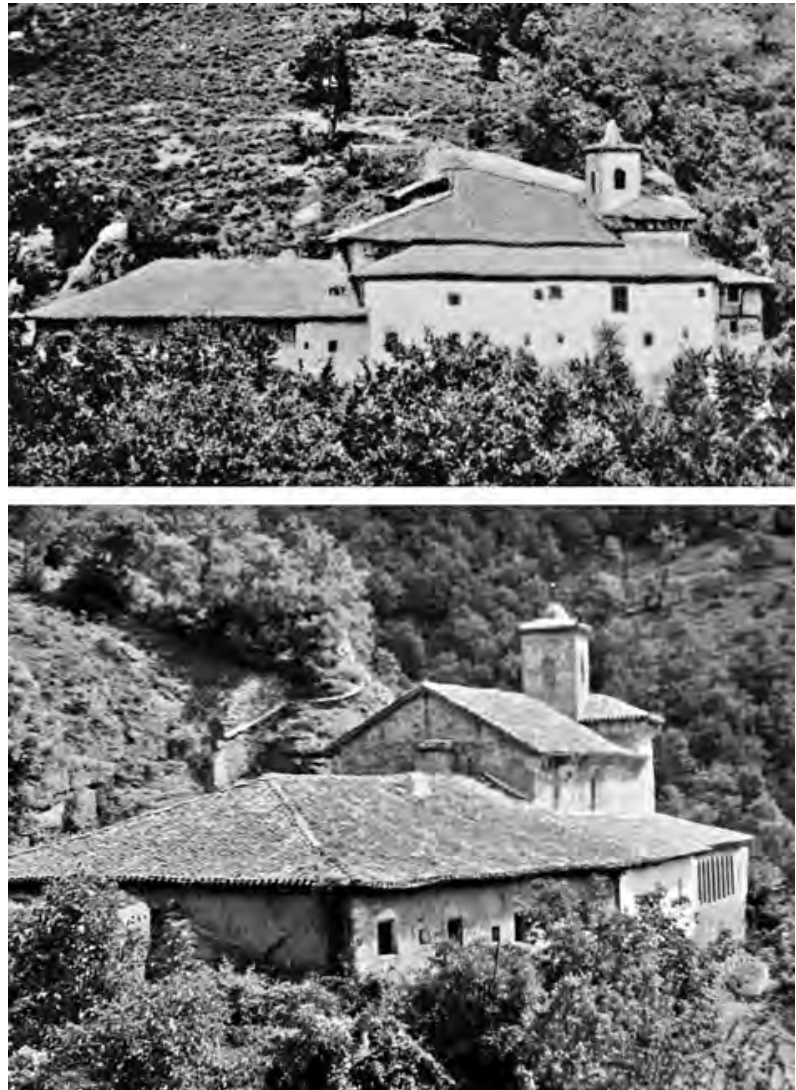

Iñiguez Almech (1901-1982). De sus escritos se puede deducir el calado de las intervenciones efectuadas en la iglesia, resumida en la "limpieza y desembarazo de lo postizo ${ }^{\prime 54}$, es decir, de todo lo posterior que ocultaba lo finalmente descubierto: "los elementos que restan de los diversos períodos, iniciados por San Millán y terminados, en lo fundamental, por Sancho el Mayor (1005-1035)" dice de la configuración del astial de los pies, ni de intervenciones en tejados u otras zonas. Recientemente el Archivo General de la Administración (Alcalá de Henares) ha descrito algunos expedientes correspondientes al monasterio de Suso,

54. URANGA, J. E. e íÑIGUEZ, F., Arte Medieval Navarro. Pamplona, Aranzadi, 1971, t. I, p. 186.

55. "San Millán de la Cogolla" en Guía-Itinerario del V Congreso de Arte de la Alta Edad Media. Ministerio de Educación Nacional, Dirección General de Bellas Artes, 1953, p. 9. Véase también íÑIGUEZ ALMECH, F., "Algunos problemas de las viejas iglesias españolas" en Cuadernos de Trabajos de la Escuela Española de Historia y Arqueología en Roma, VII (1955), pp. 9-11. 
que sacan a la luz los pocos datos de un proyecto que se consideraba perdido y que realmente no existió como tal ${ }^{56}$. Por estos documentos sabemos que Francisco Iñiguez, arquitecto conservador de la $2^{2}$ zona entre 1933 y 1936, en la que se encontraba la provincia de Logroño ${ }^{57}$, firmó un informe de una hoja el 26 de junio de 1934 en el que ponía de relieve la necesidad de estudio de la iglesia mozárabe de San Millán, ya que "posteriores modificaciones, encalados, etc." impedían su detenido reconocimiento, siendo muy interesante la resolución de los problemas que planteaba en cuanto a su configuración en planta y datación, y constatándose rastros del incendio provocado por las tropas de Almanzor en 1002. Por ello proponía una "obra de limpieza" y "exploración", como la que ya se había iniciado en San Juan de la Peña, para lo que era necesario "acometer por varios puntos todo el edificio", contando con que se podrían "producir sorpresas al levantar el yeso" de la piedra calcinada y sería conveniente contar con andamios fuertes que pudieran servir "de apeos en momentos determinados". La solicitud de 8000 pesetas fue propuesta por la Junta del Tesoro Artístico Nacional a la Dirección General de Bellas Artes el 28 de julio del mismo año. Al año siguiente, la propuesta de gasto fue de 10.000 pesetas "para obras de exploración consolidación y demoliciones de partes nuevas del Monasterio", aprobada por la Junta en su sesión del 20 de julio de 1935, tras el informe del arquitecto, fechado el 16 de abril de ese año. En él, con igual brevedad, comentaba el comienzo de la limpieza, "rascando capa por capa de enlucidos, para buscar los de tipo primitivo y las pinturas que pudiese haber en ellas", lo que había permitido definir tres etapas de construcción de la iglesia, siendo preciso continuar "la consolidación y proceder a la demolición de partes nuevas y sin arte", que tapaban los restos anteriores, al mismo tiempo que proseguía la exploración y reconocimiento de tumbas. Deja claro que no se podía "hacer proyecto de esta obra, por la necesidad de sujetarse en cada momento a lo que la misma obra" iba exigiendo. En el informe que firmó el 27 de julio de 1935 señala que las obras habían precisado ya por completo la forma primitiva de la iglesia, y todo ello estaba "necesitadísimo de consolidación, reposición de cubiertas, etc.", para lo que estimaba necesaria la concesión de una nueva consignación de 10.000 pesetas. Este gasto se tramitó por la Junta el 9 de octubre de $1935^{58}$.

56. Esta investigación se ha realizado en el marco del desarrollo del proyecto Restauración monumental y desarrollismo en España 1959-1975 (ref. HAR2011-23918), del que es investigadora principal la Dra. M. a Pilar García Cuetos (Universidad de Oviedo), con la financiación del Ministerio de Economía y Competitividad y fondos de la Unión Europea.

57. Véase ESTEBAN CHAPAPRÍA, J., La conservación del patrimonio español durante la II República (1931-1939). Barcelona, 2007, pp. 221-227, y entre otros sobre su intervención en el patrimonio aragonés, HERNÁNDEZ MARTÍNEZ, A., "Francisco Íñiguez Almech y Leopoldo Torres Balbás, ¿vidas paralelas?" en VILLAFRANCA JIMÉNEZ, M. M. y FERNÁNDEZ-BACA CASARES, R. (coord.), Leopoldo Torres Balbás y la restauración científica, Granada-Sevilla, 2013, pp. 449-476.

58. Archivo General de la Administración (en adelante AGA), sig. 65/00237. 
Muy poco sabemos sobre la conservación del monasterio de Suso en los años inmediatos a la Guerra Civil y su situación hasta la década de los sesenta. Tan sólo la concesión por Orden del 20 de marzo de 1941 de 4000 pesetas por el Ministerio de Educación Nacional, a propuesta de la Comisaría General del Patrimonio Artístico Nacional, para que el arquitecto de zona (el mismo Francisco Iñiguez, a su vez, Comisario General del Servicio de Defensa del Patrimonio) dirigiese la reparación "con carácter urgente (...) de los desperfectos ocasionados por los temporales últimos en la cubierta" de la iglesia, la cual había quedado desmantelada ${ }^{59}$. De ello se hizo eco la prensa local ${ }^{60}$. En 1943 un artículo en $A B C$ ponía de relieve la importancia de "la abadía visigótica de Suso", donde "recientes restauraciones descubrieron su arcaica labra, comprobando su antiquísima construcción" años de Restauración Monumental", organizada por la Dirección General de Bellas Artes en 1958, se señala la cantidad de 35.600 pesetas empleada en esta restauración a partir de $1938^{62}$.

Una obra que afectó al entorno histórico fue, sin duda, la carretera de acceso a Suso (LR-421), desde la actual comarcal LR-205, proyecto que debió iniciarse entre 1936 y 1939, y volvió a retomarse en 1956, solicitándose ayudas para su ejecución en $1957^{63}$. En el Archivo General de La Rioja se conserva un expediente de la Diputación Provincial de Logroño (Sección de Secretaría, Vías y Obras Provinciales) con documentación variada de las obras de desvío del camino vecinal "del de San Millán de la Cogolla al del Monasterio de Suso en la carretera de San Millán a Haro", generada entre 1957 y 1964, pero en el que no se conservan proyectos, ni planos ${ }^{64}$. Parece ser que la traza inicial arrancaba desde el monasterio de Yuso, pero en 1957 se plantea el estudio de una variante que enlazara con este camino y evitase el paso forzoso por la estrecha calle principal de la localidad, que producía taponamientos de circulación con la presencia de un solo carro. Las gestiones se inician en mayo de ese año, con la propuesta a la Diputación por la comisión de Obras Públicas y Paro Obrero del estudio de la variante, la cual fue aprobada el día 23, acordándose en el ayuntamiento de San Millán de la Cogolla la cesión de los terrenos el 4 de junio. Al año siguiente el alcalde solicitó información del estado del proyecto ${ }^{65}$,

59. AGA, sig. 65/00237 y BOE, núm. 37, de 28 de marzo de 1941, p. 2075.

60. El Najerilla, 263 (Mansilla, abril, 1941), p. 2.

61. LÓPEZ-CASTRO, C. M., "Los dos monasterios de San Millán de la Cogolla. La abadía visigótica de Suso", $A B C, 13$ de noviembre de 1943, p. 7.

62. Veinte años de Restauración Monumental. Catálogo de la Exposición. Madrid, 1958, pp. 28-29.

63. AGA, sig. 65/00237.

64. Archivo General de La Rioja (en adelante AGLR), sig. DP 893/7.

65. En febrero se encontraba a falta de algunos trabajos de delineación y en abril se remitió por la sección de Vías y Obras a la Diputación para su aprobación, con un importe de 


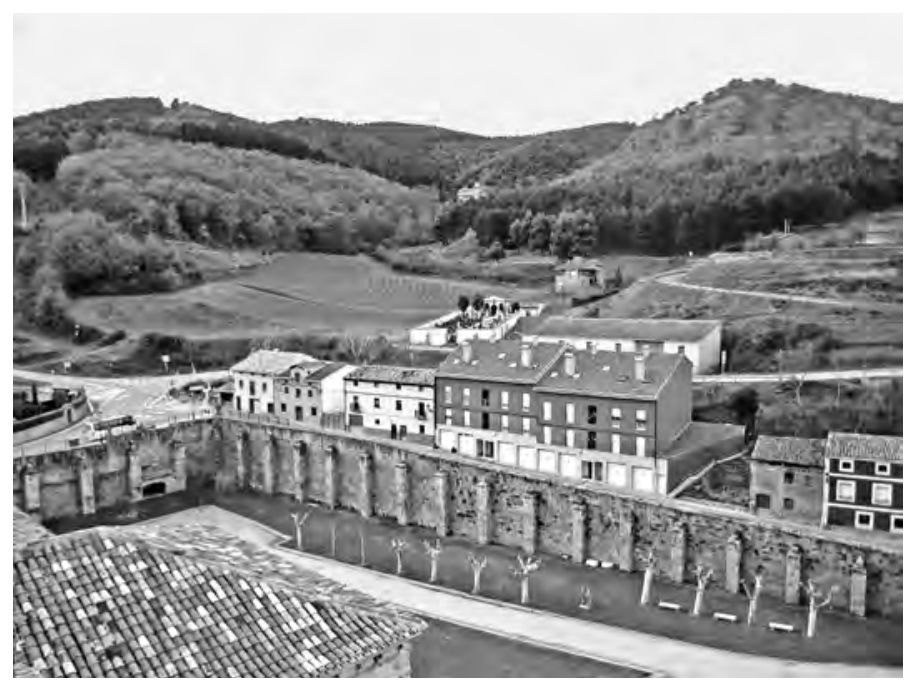

Lámina 4. Carretera de acceso a la iglesia de San Millán de Suso y entorno desde la torre de la iglesia del monasterio de Yuso, en 2006.

pero hasta 1960 no se atendió la solicitud de su puesta en marcha, dada la urgente necesidad del desvío y circunvalación por ser travesía peligrosa y de interés turístico para la Rioja. Finalmente la obra salió a subasta ${ }^{66}$, adjudicándose en agosto de 1960 e iniciándose los trabajos en octubre de ese año, los cuales se prolongaron hasta la recepción definitiva en noviembre de 1962. Para ello fue necesario el desmonte del terreno, su terraplenado, ejecución de alcantarillas, obras de fábrica y afirmado. Entre 1963 y 1965 se ejecutaron otras obras en la carretera de Berceo a San Millán y en 1967 se procedió al tratamiento asfáltico del camino a Suso ${ }^{67}$ (Lám. 4).

La restauración de cubiertas fue el objetivo del primer proyecto de intervención por parte del Ministerio de Educación Nacional, encargado al arquitecto Manuel Lorente Junquera en 1961, en cuya memoria, firmada en junio de ese año, nada menciona de las construcciones occidentales, limitándose las reparaciones, por razones económicas, al desmontado de la cubierta, la reparación del entablado con madera nueva y al retejado esencial del monumento ${ }^{68}$. Comenta que desde el interior de la iglesia se veía la armadura de la cubierta,

611.661,35 pesetas por administración y de 696.446,08 pesetas por contrata. Sin embargo, el interventor comunicó que no estaba incluido en ninguno de los planes de carreteras y caminos vecinales de ese año.

66. BOR, 28 de junio de 1960, núm. 71.

67. AGLR, sig. DP 893/8 y DP 893/9.

68. AGA, (03)115 IDD 26/359. El proyecto aprobado por Orden del 16 de septiembre de 1961 se publicó en el BOE del 12 de enero de 1962 (núm. 11, p. 581), con un importe total de $45.231,29$ pesetas. 
sencilla y en estado muy deficiente, origen de las consiguientes goteras. Dibuja una sección señalando que el caballete cortaba el "muy bello alero pétreo", por lo que en su día se debería someter la cubierta a una reforma total. Es probable que la fotografía tomada por Gonzalo de Miguel corresponda a un momento posterior a esta intervención, dado el aparente buen estado de los tejados y su uniformidad (véase lám. 3). En ella puede observarse también la pervivencia del importante volumen de las construcciones occidentales, adosadas a los muros de la iglesia y pórtico, sobresaliendo de su tejado a tres aguas el contrafuerte existente en el de la primera.

Otro periodo de algo más de diez años transcurrió hasta la siguiente intervención documentada. Probablemente los edificios conventuales prosiguieron su forzado abandono, por lo que no es de extrañar que se produjeran robos, como el de la Virgen con Niño en el verano de $1964^{69}$, hecho reflejado en la prensa nacional ${ }^{70}$.

En 1967, según el padre Peña, se destruyó la parte que habitaron los mon$\mathrm{jes}^{71}$. No se ha encontrado ninguna referencia documental a este hecho, sin embargo en ese año el arquitecto provincial Antonio Fernández Ruiz-Navarro redactó por encargo de la Diputación Provincial el proyecto de refugio para el guarda del monasterio de Suso, "con el fin de mejorar las condiciones del servicio" que prestaba, según la memoria firmada en Logroño en el mes de abril. Nada se dice en ella de otras dependencias, excepto del museo adosado a la iglesia, en el que, aprovechando una de las dos ventanas existentes, se habilitaría un departamento de 3,30 × 4 m, al que se le daría acceso por el porche, para que el guarda pudiese controlar las visitas. Así mismo, se construiría una chimenea de campana y se renovarían el pavimento y las carpinterías de la puerta de acceso, ventanillo, etc. ${ }^{72}$. Por el plano que presenta (escala 1:100), la chimenea se adosaría al muro sur de la iglesia, el tabique divisorio de ladrillo se iniciaría próximo a la puerta de acceso desde la iglesia a la dependencia del

69. Según Alejandro Manzanares la policía de París detuvo a comienzos de diciembre a Alain Michel, natural de Poitiers, con objetos robados procedentes de Suso "dos vidrios artísticos, con el Niño, y una estatuilla de la Virgen, asimismo con Niño" (MANZANARES, A., Valle de San Millán. Monumentos, paisajes y costumbres. Logroño, 1965, s/p (cap. "El Monasterio de Suso", nota 1).

70. H. P., "Han sido recuperadas en Francia varias obras de arte sustraídas en España. El ladrón al parecer cleptómano, las tenía en una especie de museo suyo", $A B C$, no 19.262, 29 de mayo de 1965, edición de Andalucía, p. 42; "Recuperación de obras de arte robadas por un fotógrafo de Poitiers en iglesias y monasterios españoles", La Vanguardia Española, 29 de mayo de 1965, p. 5. Las gestiones las realizó la Dirección General de Bellas Artes a través del Ministerio de Asuntos Exteriores, encomendándose la identificación de los objetos robados a Xavier de Salas, subdirector del Museo del Prado. Agradezco estas referencias a M.․ㅡ Jesús Martínez Ocio.

71. PEÑA, J., Páginas emilianenses. Salamanca, 1972, Apéndice 3, p. 181, y San Millán de la Cogolla..., reed. 1994, p. 259.

72. AGLR, sig. 659/1. El presupuesto ascendía a 28.965,82 pesetas. 
guarda, y ésta se prolongaba hacia el oeste más allá del muro de cierre occidental de la iglesia, donde no se dibuja ninguna otra construcción. En las mediciones se detallan en el capítulo de derribos y demoliciones las aperturas de huecos para sendas puerta y ventana de vigilancia en la pared del museo. Todavía en 2000 se podía ver la huella de la cocina hogar con campana de gases proyectada, que se haría con salida de humos de fábrica de ladrillo y remate completo de chimenea. Llama la atención entre las obras presupuestadas, además de la baldosa cerámica de pavimentación, enlucidos de mortero hidráulico y de yeso, la grada de piedra en la puerta de acceso al refugio, la carpintería de pino o el rodapié, la recogida de faltas en el pavimento de empedrado del pórtico. Queda la duda de si el derribo de la casa conventual siguió a esta intervención, o formó parte de ella.

El 17 de octubre de 1973 la Dirección General de Bellas Artes aprobó las obras urgentes a realizar en el monasterio de $\mathrm{Suso}^{73}$. El 18 de mayo de ese año el director del Museo Provincial de Logroño, Rafael Puertas Tricas, firmaba una memoria en la que sintetizaban los caracteres y mérito artístico del monumento y proponía las obras a realizar, motivadas por los temporales de los meses de abril y mayo que habían agravado las deficiencias que ya señaló en un informe del 12 de febrero, urgiendo la restauración de los daños, fundamentalmente referidos al hundimiento de pequeñas zonas de tejado que ocasionaron grietas y goteras. La colocación provisional de plásticos requería soluciones más duraderas, por lo que proponía el repaso general de las cubiertas, con sustitución de tejas; la disposición de dos cabrios nuevos y el "alquitranamiento de toda la zona oeste, incluida la cubierta de la capilla osario y zonas colaterales", que se encontraba revestida de cemento, "muy agrietado por efecto de las heladas", lo que había provocado numerosas filtraciones que afectaban a la estructura del edificio. El presupuesto firmado por el arquitecto Eduardo González Mercadé en la misma fecha, ascendía a 250.000 pesetas, en las que se incluía el repaso de un $60 \%$ de las cubiertas y sustitución del $20 \%$ de teja, la colocación de 6 cabrios y la impermeabilización con tela asfáltica sobre solera de hormigón. Las fotografías del museo muestran el estado de las cubiertas, las grietas en la fábrica bajo el alero mozárabe, otras en la torre, y la situación del nivel situado por encima de las cubiertas, señalando el pie de ésta última la necesidad de limpieza. En la misma fecha otro proyecto se centraba en las obras urgentes en los anejos al monasterio $^{74}$. El director del museo señalaba: "Por las mismas razones apuntadas en la 'Memoria sobre obras urgentes de restauración...', todos los muros que quedaban en pie de la moderna hospedería adosada al monasterio de San Millán de Suso, amenazan ruina, con el consiguiente peligro para los turistas que visitan por aquella zona, y que no pueden ser controlados por el guarda en los días de

73. AGA, (03)115 IDD 26/00034.

74. AGA, (03)115 IDD 26/00034. 
gran afluencia de público". Por ello proponía: "I. derribo de todos los muros de la mencionada hospedería convirtiendo toda aquella zona en una explanada que puede dedicarse a jardín; II. Como consecuencia de estos derribos queda totalmente al descubierto el muro sur del monasterio, en buen estado de conservación. Sería sin embargo conveniente, repasar todas las junturas de los sillares, así como el revocar las zonas de ladrillo que hay actualmente (que corresponden a la reconstrucción moderna del pórtico). Convendría igualmente, cerrar los huecos, que como consecuencia del derribo de la hospedería quedarían al descubierto; III. Sería necesario derribar parte de la tapia moderna adosada a la fachada de entrada al monasterio, que afea notablemente la vista del mismo". El arquitecto González Mercadé presupuestó otras 250.000 pesetas para estos trabajos, incluyendo, la demolición de la tapia, de los muros de la hospedería con explanación de la zona, el rejuntado de sillares del muro sur y el mayor monto (165.375 pts.) de la construcción de un muro de cantería, compuesto por fábrica mixta de mampostería y trasdós de hormigón en masa.

Así, el acceso oriental se ordenó y adecentó, se enfoscaron y pintaron de ocre los pilares de ladrillo de la inventada arquería meridional y se explanó la zona que ocupaba el convento, quedando la fachada occidental mutilada, sin sentido, cortado y cegado el uso de sus vanos, y con ello la historia del edificio y del verdadero significado de su designación como Patrimonio de la Humanidad. Si atendemos a la fotografía que publica Alejandro Manzanares en 1965, el acceso a las cuevas superiores, a las que también se llegaba desde el interior de la iglesia, estaba cerrado por un vano carpanel con reja, de rosca de ladrillo a sardinel y salmeres apoyados en la roca al norte y en un pilar de sillería al sur, en el que apeaba la rosca de otro arco gemelo, cegado. Ambos se abrían en un muro de mampostería, rematado con hiladas de ladrillo, que corría de sur a norte, enjarjándose en la fachada occidental de la iglesia, correspondiente al tramo de ampliación románica. El espacio se muestra al aire libre, creando un patio abierto con acceso desde la iglesia y desde la casa conventual, probablemente la puerta norte que dibuja Ruiz-Navarro en la dependencia del guarda. En la fotografía se observan parte de los tejados de la casa (Lám. 5) ${ }^{75}$. En 1973 no debía quedar nada de ello. Las siete fotografías del museo provincial (ningún plano) que acompañan el segundo proyecto de 1973 muestran detalles de la necesidad de consolidar algunas zonas de la cimentación y sillares de la parte baja, los recientes derrumbamientos y el aspecto que presentaban los muros de la hospedería moderna, los cuales dejaban al descubierto el astial occidental de la iglesia, cegados sus dos vanos meridionales (el superior con madera y el inferior con cascotes) y muy arruinado el contrafuerte, habiéndose alineado el cerramiento de la dependencia del guarda con dos tipos de aparejo de ladrillo.

75. MANZANARES, A., Valle de San Millán..., cap. "Las cuevas del Santo", pie de foto: "cueva donde el Santo hacía rigurosa penitencia". 

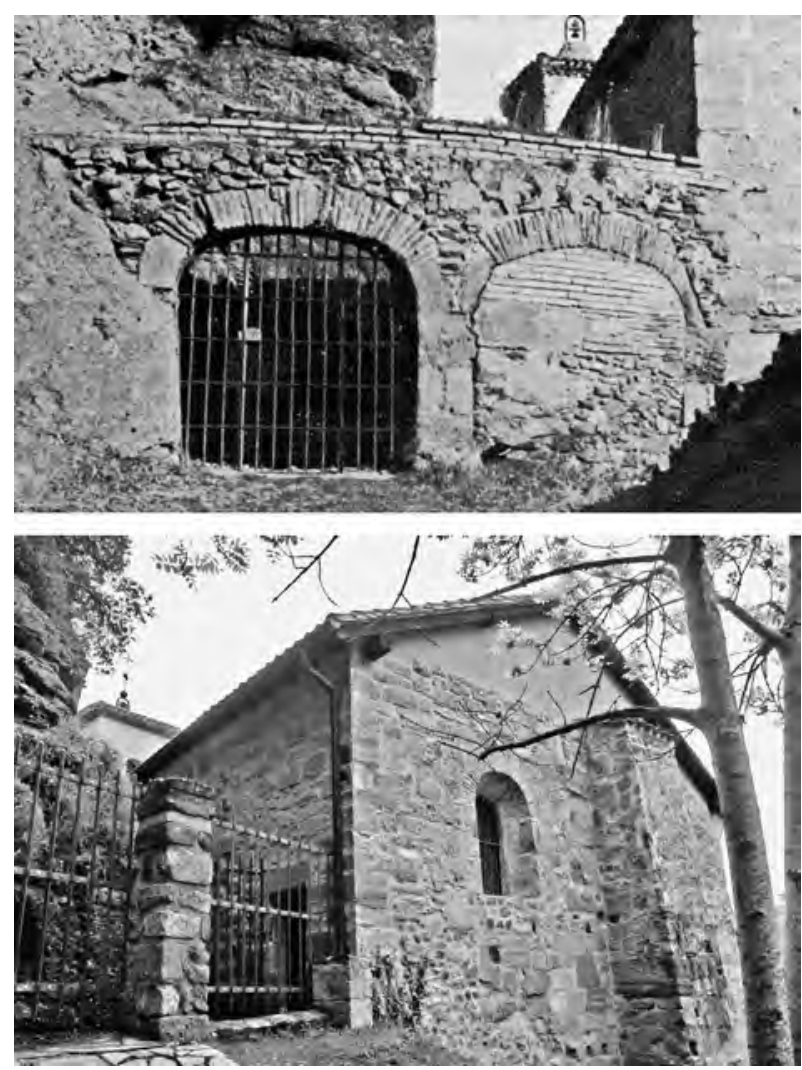

Lámina 5. Vista de la zona occidental de la iglesia de San Millán de Suso y acceso a las cuevas superiores. Arriba, antes de los derribos de 1967 (en Manzanares, A., Valle de San Millán. Monumentos, paisajes y costumbres. Logroño, 1965, s/p); abajo, en 2013.

Aún quedaba parte del alzado del muro sur del piso alto del convento, de mampostería enfoscada y enlucida, y algo se veía de una fábrica en la planta inferior con vanos cercados de sillería, probablemente anterior, entre la frondosa vegetación que había invadido el espacio dejado por los arruinados muros perimetrales. A estas actuaciones parece deberse el escombrado de una estancia situada bajo la dependencia del guarda, que se había mantenido en uso hasta 1967, partida por un muro de hormigón, y que fue excavada por los hermanos Sáenz Preciado en $1996^{76}$. Sólo el sondeo arqueológico de este espacio semisubterráneo de la dependencia del guarda, interpretado como parte de una antigua cuadra, permitió conocer el estado de la cimentación, la existencia de un pozo ciego de algo más de un metro con huesos animales y cerámica estannífera de los siglos XVIII-XIX, y un muro de sillares en dirección oeste-este, rela-

76. SÁENZ PRECIADO, M. P., "Arqueología...", pp. 151 y 153-154 y SÁENZ PRECIADO, M. P. y SÁENZ PRECIADO, J. C., "Seguimiento y sondeos...", pp. 65-66. 
Lámina 6. Fachada meridional de la iglesia de San Millán de Suso y restos de los muros del convento, en 2013.

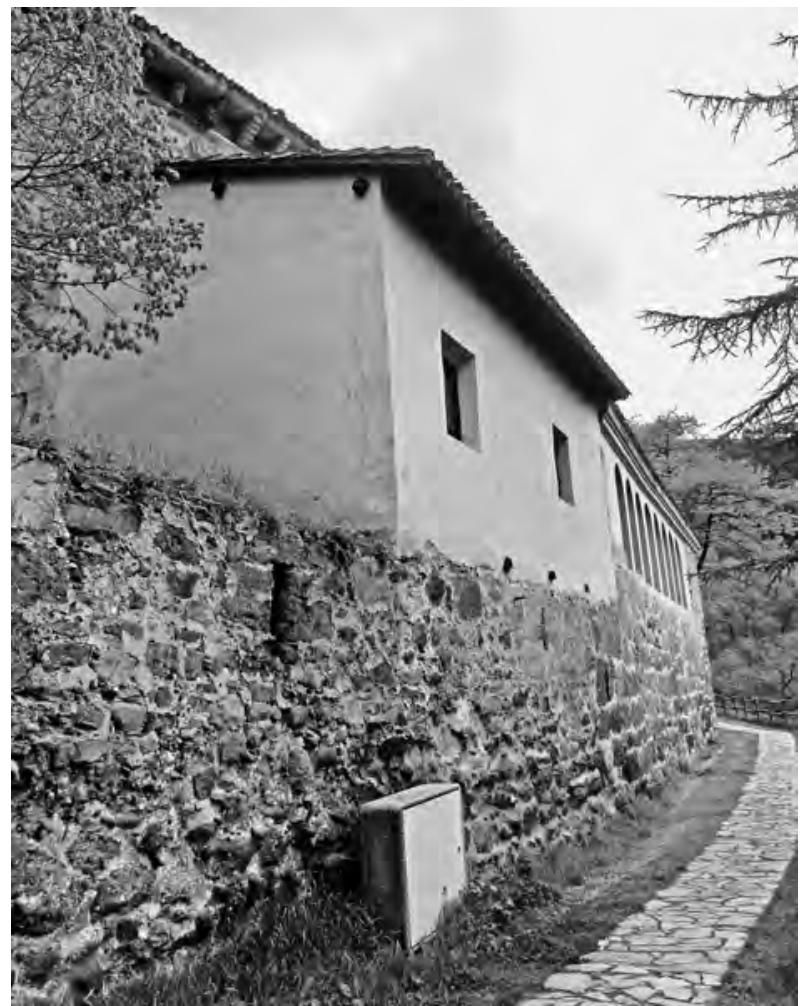

cionándose con él fragmentos de ollas medievales de cocción reductora, datadas en los siglos XI-XII. Es decir, la importancia de la fachada sur no parece haberse tenido en cuenta realmente en las actuaciones referidas a la zona de museo y dependencia del guarda, repetidamente remodeladas, habiéndose perdido mucha información histórica (Lám. 6). Ni qué decir tiene de la casa conventual, su salón, chimenea, celdas, cenador, escusado, jardín, huerta, fuente, etc., de los que nos hablan las fuentes manuscritas, ni de las remotas construcciones que se diseminaban por la dehesa de Suso y alrededores.

La intervención de Fernando Chueca Goitia, según la memoria de noviembre de 1978 para la restauración parcial de la iglesia, al margen de desmontar las cubiertas y consolidar los aleros, se extendió a la consolidación y recalce de algunas grutas, la reparación del pavimento de iglesia y atrios, y a la limpieza de broza de los alrededores, estudiando un posible drenaje por medio de zanjas y alcantarillas bufas ${ }^{77}$. Desaparecieron finalmente las estructuras anti- 
guas en las cubiertas y las nuevas tuvieron que rehacerse casi en su totalidad veinte años después ${ }^{78}$.

Puesto que ninguna importancia se había dado a las construcciones al sur y oeste de la iglesia, ningún dato más se puede recabar del convento de Suso. Sólo cabe lamentar que todas las actuaciones en relación con el museo y refugio del guarda, así como los derribos de la casa monástica, se hicieran sin ningún proyecto ni control aparente, como el que deja arruinar una construcción sin importancia, ni valores históricos, bajo la cual se podrían haber estudiado más de un indicio de su devenir que, al menos, remontaba al periodo medieval, si no anterior. Porque ¿cómo se entiende el escritorio y la vida conventual sólo con la iglesia? ¿Cómo se sigue repitiendo que el pórtico es el "portaleyo" donde escribió Gonzalo de Berceo, cuando sabemos que la arcada actual es obra de 1934-1935? El trabajo de Puertas Tricas de 1979 ya puso de manifiesto la complejidad de datación que los, desde la intervención de Íñiguez, descarnados muros de la iglesia presentaban ${ }^{79}$, y la nueva revisión de Caballero Zoreda de 2002 ha permitido confirmar algunos supuestos, no sin dejar de poner de relieve la necesaria unión entre las actuaciones restauradoras y las investigaciones arqueológicas ${ }^{80}$, situación manifestada también desde la arquitectura, en general por la escasez de medios materiales. ¿Qué podemos decir desde la historia del arte, cuando los informes histórico-artísticos nunca han estado presentes en los proyectos de un monumento de tal categoría, -por falta de presupuesto-, pese al acuerdo unánime de la necesidad del estudio documental previo y exhaustivo del patrimonio a restaurar?. La problemática de conservación de la iglesia de Suso ya se hizo evidente de forma alarmante a finales del siglo $X X^{81}$, y todavía las incógnitas sobre el pasado del monumento son muchas y de la pervivencia de lo que de él hemos dejado, preocupantes.

78. SANCHO RODA, J., "Monasterio de San Millán de la Cogolla de Suso. La Rioja", Quaderns Cientifics i Tècnics, 4: Il Simposi, Actuacions en el patrimonio edificat.: la restauració de I'arquitectura dels segles IX i X (Investigació histórica i disseny arquitectònic), Barcelona, 1992, pp. 62-66.

79. PUERTAS TRICAS, R., Planimetría de San Millán de Suso. Logroño, Instituto de Estudios Riojanos, 1979 (véanse láminas 1 a 3 y 18 para el entorno).

80. CABALLERO ZOREDA, L., "La iglesia de San Millán de la Cogolla de Suso. Lectura de paramentos 2002", en GIL-DÍEZ USANDIZAGA, I. (coord.), VIII Jornadas de Arte y Patrimonio Regional. Arte Medieval en La Rioja: Prerrománico y Románico, Logroño, 2004, pp. 13-93.

81. Véanse referencias en ARRÚE UGARTE, B., "Conservación del monasterio...", p. 521, nota 2. 